\title{
Proposta de método otimizado para a avaliação de desempenho em uso de sistemas construtivos inovadores
}

\author{
Proposal for an optimised method for evaluating the \\ performance in use of innovative construction systems
}

\section{Mena Cristina Marcolino Mendes Márcio Minto Fabricio César Imai}

\section{Resumo}

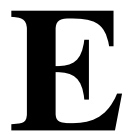

ste artigo busca discutir o desempenho em uso dos sistemas construtivos inovadores (SCIs), homologados por instituições técnicas avaliadoras (ITAs) e pelo Sistema Nacional de Avaliação Técnica (SiNAT). O objetivo foi analisar os resultados de avaliações pósocupação (APOs) em habitações de interesse social (HISs) construídas em concreto-PVC e sistema leve em madeira, a partir da proposta de otimização e do critério avaliativo das falhas sistemáticas de um conjunto de instrumentos, sendo: projeto, obra, manual de uso, operação e manutenção, manutenibilidade e assistência técnica (FINANCIADORA..., 2012). Nos dois casos, a estanqueidade é o fator de desempenho que mais requer intervenções nas HISs. Quanto às fissuras em juntas e aos problemas em caixilhos das esquadrias, não são oriundos de deformações das vedações autoportantes, o que é positivo na análise do fator de desempenho segurança estrutural. Os resultados demonstram que, embora o fator de segurança estrutural seja satisfatório, é necessária a manutenção por parte dos usuários e da assistência técnica da empresa, como no caso do sistema em concreto-PVC. Conclui-se que o método otimizado pode indicar as falhas sistemáticas dos SCIs, possibilitando recomendar às ITAs os itens prioritários para futura reavaliação.

Palavras-chave: Desempenho em uso. Sistema construtivo inovador. Avaliação pósocupação.

\begin{abstract}
This paper discusses the performance in use of innovative construction systems (ICSs), approved by Technical Assessment Institutions (TAIs) and the National Technical Assessment System (SiNAT). The objective was to analyse the results of Post-Occupancy Evaluations (POEs) in Social Housing units (SHUs) built with PVC-concrete and Light Wood Systems. The analysis was based on an optimisation proposal and on evaluation criteria established to identify the systematic failures of a set of tools: design, construction works, use, operation and

maintenance, maintainability and technical assistance (FINANCIADORA..., 2012). In both cases, airtightness was identified as the performance factor that most required intervention in the HISs. Joint cracks and frame problems were found not to be derived from self-supporting seal deformations, which is a positive aspect in the analysis of the structural safety performance factor. The results show that, although the structural safety factor is satisfactory, there is need for maintenance by users and for technical assistance by the manufacturer and/or the construction company, as in the case of the Concrete-PVC system. The results showed that the proposed optimised method is capable of identifying systematic failures in the ICSs, allowing for recommendations to be made to the technical assessment institutions as for which items should be prioritised in future reevaluation of the construction systems.
\end{abstract}

${ }^{1}$ Mena Cristina Marcolino Mendes ${ }^{1}$ Universidade Estadual de Maringá Maringá - PR - Brasil

${ }^{2}$ Márcio Minto Fabricio ${ }_{2}^{2}$ Instituto de Arquitetura e Urbanismo São Carlos - SP - Brasil

${ }^{3}$ César Imai ${ }^{3}$ Universidade Estadual de Londrina Londrina - PR - Brasil

Recebido em 08/04/19 Aceito em 21/12/19
Keywords: Performance in use. Innovative construction systems. Post-occupancy evaluation.

MENDES, M. C. M.; FABRICIO, M. M.; IMAI, C. Proposta de método otimizado para a avaliação de desempenho em 


\section{Introdução}

A habitação é reconhecida como uma necessidade básica, devido ao seu papel fundamental no desenvolvimento humano, social e econômico de um país. Por essa razão, o acesso à moradia é enfatizado em diferentes políticas governamentais. Ademais, o investimento no setor habitacional pode promover o bemestar da população e minimizar os efeitos negativos ocasionados pelas ocupações irregulares, pela falta de infraestrutura e pelo crescimento desordenado das cidades brasileiras. Por essas razões, o investimento no setor habitacional é estimulado pelas políticas públicas e visa reduzir o déficit habitacional, cuja percentagem em zonas urbanas, para renda de até 3 salários mínimos, apresentou-se no ano de 2014 com aproximadamente 84\%, conforme a Fundação João Pinheiro (2016).

O Programa Minha Casa Minha Vida (PMCMV), do Governo Federal, desde 2009, subsidia a aquisição da casa própria para famílias com renda familiar considerada baixa (RUBIN; BOLFE, 2014; TUROK, 2016). Atualmente o PMCMV, no Brasil, incentiva a produção de habitação social e a inserção de novas tecnologias construtivas dentro do contexto econômico do país e, portanto, tem se caracterizado como um programa de grande produção habitacional. No entanto, vários pesquisadores destacam que a qualidade do projeto oriundo da produção em grande escala não alcança as necessidades reais dos cidadãos urbanos, nem a qualidade da moradia e os serviços relacionados à habitação (PINTO; MEDVEDOVSKI, 2015; BUCKLEY; KALLERGIS; WAINER, 2016). Vale ressaltar que, no que tange ao projeto, as características regionais e culturais da população devem ser consideradas (BRANDÃO; HEINECK, 2003).

Ao considerar a inserção de novas tecnologias construtivas na habitação, apontamos o conceito de inovação tecnológica no Brasil, que, conforme a NBR 15575-1 (ABNT, 2013), é entendido como o aperfeiçoamento tecnológico resultante de atividades de pesquisa, aplicado ao processo de produção do edifício para a melhoria de seu desempenho, da sua qualidade e do custo do edifício ou de um sistema (ABNT, 2013, p. 08). As inovações predominantes do setor da construção civil brasileira são consideradas incrementais de ciclos longos, pela especificidade do produto, pelas avaliações técnicas e pela implementação e difusão da tecnologia (FLORIANI; BEUREN; HEIN, 2010). Por outro lado, em países europeus, a tecnologia da construção deve atender aos requisitos dos clientes e usuários, além de melhorar a sustentabilidade e a eficiência energética da construção, transformando as práticas e os métodos tradicionais em técnicas mais eficientes, baseadas em novos conhecimentos sobre materiais e processos de construção. Em outros países, como os Estados Unidos, China e Índia, por exemplo, a inovação no processo de desenvolvimento de produtos faz parte do processo de projeto das empresas de construção (EUROPEAN..., 2009).

Ao considerar a demanda gerada pelo programa MCMV, é notória a importância da inovação e aplicação de sistemas construtivos pré-fabricados, que trazem como característica a rapidez e podem promover a qualidade do produto. Porém, as novas tecnologias aplicadas em habitação de interesse social (HIS), embora possuam diretrizes e documentos de avaliação técnica, não contemplam as avaliações para a homologação do comportamento em uso dos sistemas construtivos (MENDES, 2018). Sendo assim, o artigo apresenta a continuidade da discussão sobre o desenvolvimento de métodos e metodologias para a avaliação dos sistemas inovadores homologados pelo Sistema Nacional de Avaliação Técnica (SiNAT), iniciada no âmbito do Projeto Inovatec da Financiadora de Estudos e Projetos (FINANCIADORA..., 2012) e abordada em diversas publicações (AMANCIO et al., 2015; AMANCIO, FABRICIO, 2015; ONO et al., 2015, 2017a, 2017b; ORNSTEIN et al., 2017). No contexto da avaliação dos SCIs, os critérios para a verificação das falhas sistemáticas podem contribuir para a reavaliação do sistema, bem como para futuras complementações das diretrizes e normativas. Portanto, o presente estudo propõe um critério avaliativo para as falhas sistemáticas, pautada na avaliação de desempenho em uso de sistemas construtivos inovadores (SCIs), a partir de procedimentos consolidados e otimizados de APO.

Este artigo teve por objetivo analisar os resultados de APOs e aprimorar o método de avaliação de desempenho para os sistemas construtivos inovadores, buscando otimizar os instrumentos a partir da aplicação sistemática em dois empreendimentos habitacionais de interesse social diferenciados pela tecnologia: painéis de PVC preenchidos com concreto armado moldado no local e painéis leves em madeira.

\section{Avaliação de desempenho de sistemas construtivos inovadores}

A avaliação de desempenho, conforme a NBR 15575 (ABNT, 2013), busca analisar a adequação ao uso de um sistema construtivo. Para tanto, recomenda-se que a análise seja sistemática, baseada nos requisitos e em métodos avaliativos da referida norma, reproduzindo o comportamento do sistema nas diversas condições de 
uso. No ano de 2018 iniciou-se um estudo técnico para a revisão da referida norma, o que fortalece a importância de pesquisas nesse âmbito.

Para o caso específico dos sistemas construtivos inovadores, o Sistema Nacional de Avaliação Técnica (SiNAT) contribui para demonstrar a qualidade e o desempenho de um produto inovador em um primeiro momento. Toma-se como exemplo a publicação da "Diretriz de Avaliação Técnica para sistemas construtivos em paredes de concreto moldadas no local”, pelo SiNAT, que foi a base para a confecção da norma ABNT NBR 16055 (ABNT, 2012b).

O Sistema Leve em Madeira possui uma “Diretriz de Avaliação Técnica” publicada pelo SiNAT e, desde o ano de 2016, há uma Comissão de Estudo do Comitê Brasileiro da Construção Civil (ABNT/CB-002). Esta é responsável pela discussão da norma brasileira, com ênfase no projeto, na execução, nos requisitos gerais e nos componentes para a construção em madeira.

Em geral, os DATecs dos sistemas construtivos estudados enfatizam a necessidade de verificação do comportamento, em uso, das interfaces das paredes e painéis de vedação com os diversos sistemas convencionais. Além disso, também inspecionam seu desempenho, tais como a isolação sonora de uma esquadria ou o monitoramento das juntas de um painel de vedação. Entretanto, os referidos documentos técnicos não indicam como realizar essas verificações.

A qualidade da habitação está relacionada às características físicas da moradia e à percepção dos moradores, como satisfação, aspirações e possíveis desapontamentos dos usuários, entre outros aspectos a serem avaliados, como: serviços de apoio, do ambiente social, dos equipamentos públicos, vizinhança, aspectos sociodemográficos e pessoais do usuário, baseados no padrão de qualidade da habitação. Isso possibilita ao indivíduo comparar o ambiente real com a habitação ideal (MOHIT; NAZYDDAH, 2011). Portanto, a avaliação pós-ocupação (APO) pode complementar a avaliação técnica de desempenho. A APO contempla um conjunto de métodos e técnicas aplicados em ambientes construídos, em uso, podendo gerar informações e conhecimento. Dada a complexidade da APO, essas avaliações requerem diferentes métodos e levantamentos (KOWALTOWSKI et al., 2013).

Na avaliação da manutenção os instrumentos que podem contribuir para a verificação do desempenho técnico, uma vez que a NBR 15575 (ABNT, 2013) não apresenta critérios para essa análise, tem-se a percepção do usuário, do gestor (síndico), do responsável técnico pela construção e do profissional do serviço de assistência técnica (FABRÍCIO; LIMA; SANCHES, 2013).

\section{Método de pesquisa}

Neste estudo, adotou-se a APO do tipo diagnóstica como estratégia de pesquisa, pois o foco está nos aspectos de desempenho e na verificação da ocorrência de problemas sistêmicos (PREISER, 1995). A APO utilizou diferentes fontes de dados, tais como a avaliação do projeto, a verificação da obra, a avaliação do manual de uso, operação e manutenção, a avaliação da manutenibilidade, a assistência técnica e o questionário ao morador. Para Villa e Ornstein (2013), a APO contribui para identificar ações que possibilitam a melhoria contínua do produto. Nesse sentido, o método otimizado proposto e apresentado neste artigo tem o objetivo de encaminhar recomendações sobre os aspectos de projeto, da obra (in loco) e da manutenção. A Figura 1 apresenta as principais etapas da pesquisa.

\section{Figura 1 - Delineamento da pesquisa}

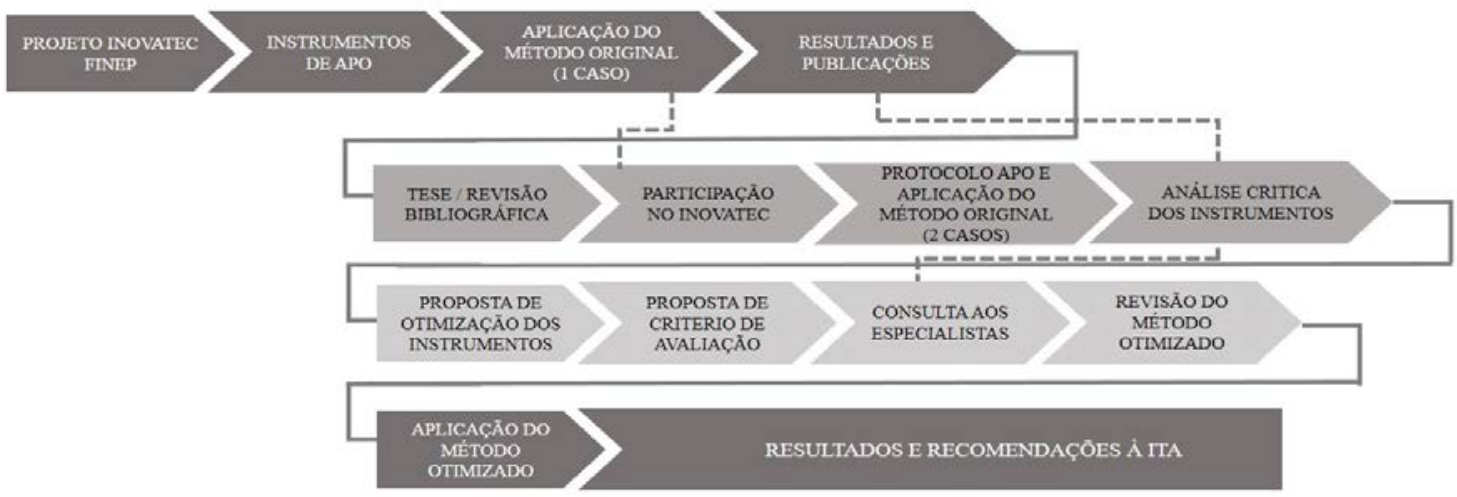




\section{Caracterização dos sistemas construtivos e das moradias}

O sistema construtivo, denominado concreto-PVC, é moldado em concreto armado, in loco, em perfis (formas) de PVC. A fabricação dos perfis de PVC é industrial e modulada. Os perfis, quando montados na obra, constituem-se nas formas para serem armados e concretados em canteiro, formando as vedações estruturais. O sistema de concreto-PVC não necessita de revestimento convencional nem pintura, uma vez que as formas dos perfis de PVC ficam incorporadas à construção, sendo o material PVC o acabamento externo. Esse sistema foi considerado inovador, tendo sido avaliado pelo Instituto de Pesquisas Tecnológicas do Estado de São Paulo e obtido o DATec n. 17 (INSTITUTO DE PESQUISA..., 2013), conforme a Diretriz n. 04 do SiNAT (BRASIL, 2010).

O sistema leve em madeira é formado por quadros estruturais de madeira serrada e tratada, com fechamento em chapa de Oriented Strand Board (OSB). Os quadros formam os painéis estruturais, que são ligados à fundação (impermeabilizada) por meio de chumbadores e de conectores metálicos entre si, resistentes à corrosão. Internamente as paredes são revestidas com placa de gesso e revestimentos cerâmicos. Externamente, as paredes são revestidas com placas cimentícias, e as juntas entre os painéis recebem o acabamento na obra. O sistema construtivo dos painéis de vedação é considerado inovador e obteve o DATec de n. 20 (INSTITUTO FALCÃO..., 2013), conforme a Diretriz n. 05 (BRASIL, 2011).

As unidades habitacionais (UHs) construídas com painéis de concreto-PVC possuem 36,20 m² de área total e foram executadas no ano de 2008. O conjunto habitacional possui 23 moradias térreas isoladas no lote, apresenta apenas uma tipologia construtiva e localiza-se na Região Sul do país. O programa de necessidades possui 2 quartos, sala e cozinha conjugada, banheiro e área de serviço externa (Figura 2). Ademais, esse programa não atende à acessibilidade conforme ABNT NBR 9050 (ABNT, 2015).

As UHs construídas com painéis leves em madeira possuem 42,80 $\mathrm{m}^{2}$ de área total e foram executadas no ano de 2014. O conjunto habitacional possui, no total, 66 moradias térreas geminadas e isoladas no lote, localizase na Região Sul do país e foi financiado pelo programa MCMV. O programa de necessidades possui 2 quartos, sala e cozinha conjugada, banheiro e área de serviço externa (Figura 3), além disso, atende à acessibilidade conforme NBR 9050 (ABNT, 2015).

Figura 2 - Planta baixa e unidade habitacional executada em painéis de concreto-PVC
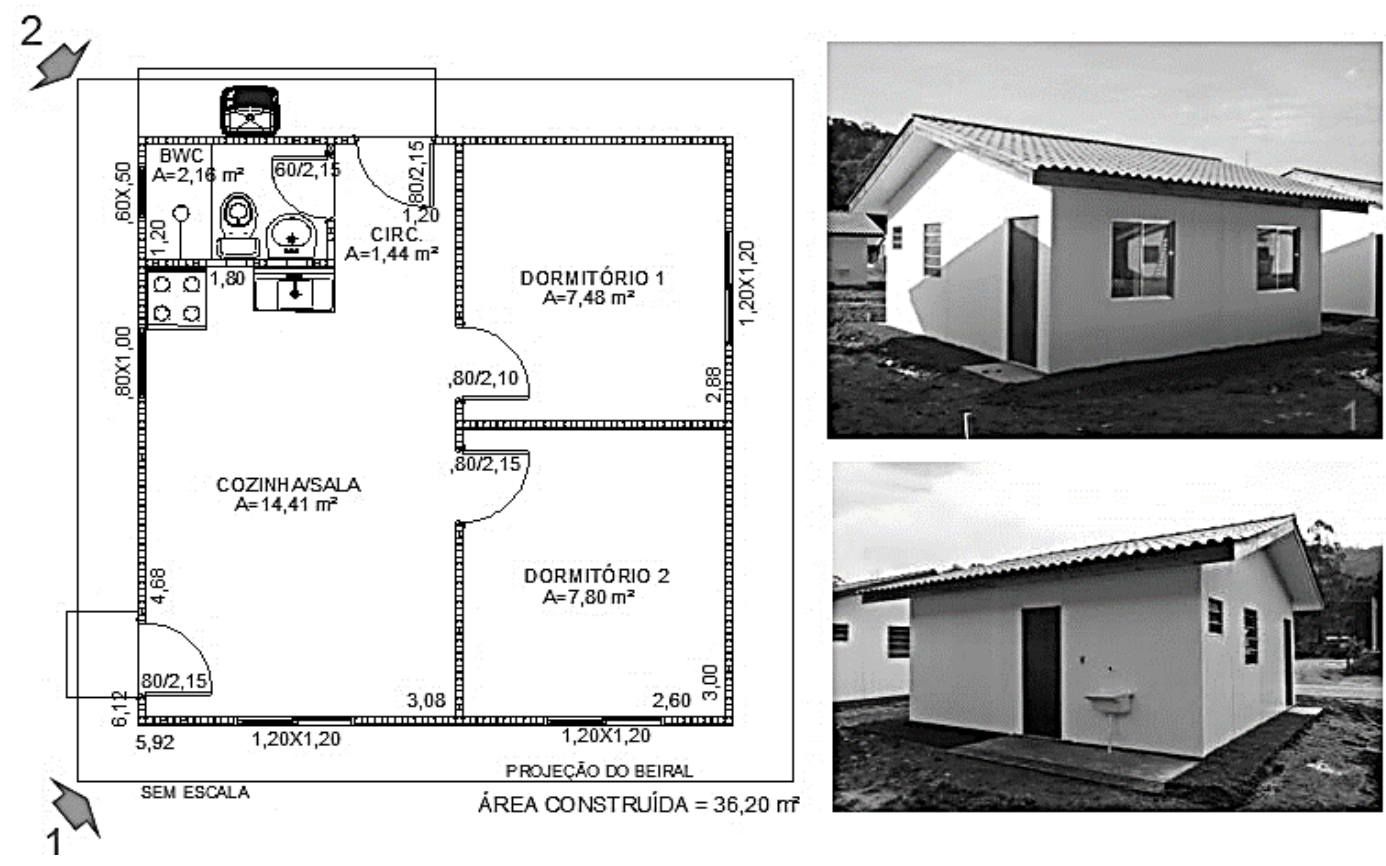

Fonte: imagens cedidas pela empresa e adaptadas pelos autores. 
Figura 3 - Planta baixa e UH executada em sistema leve em madeira

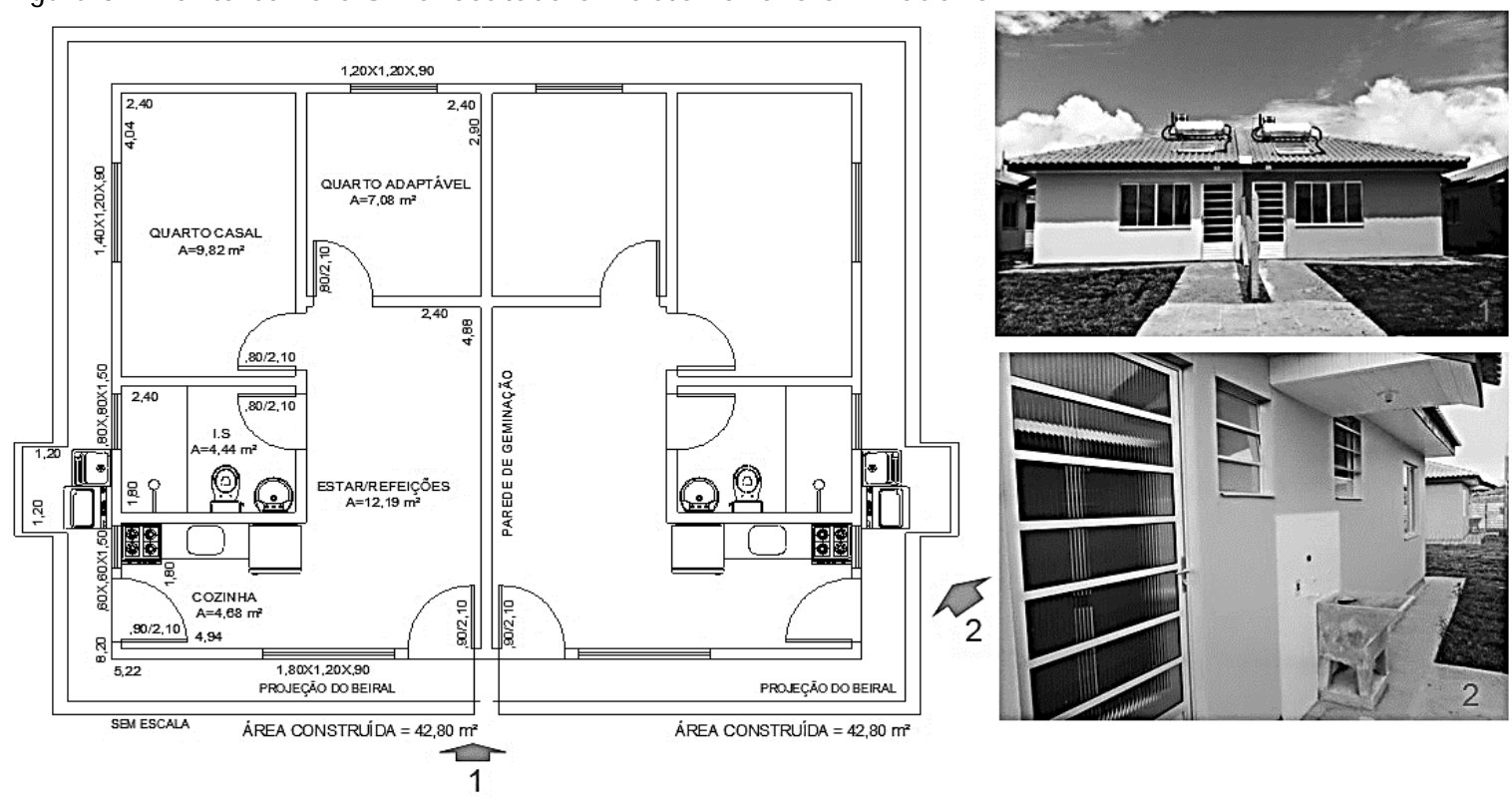

Fonte: imagens cedidas pela empresa e adaptadas pelos autores.

\section{Instrumentos da pesquisa}

O instrumento ficha de verificação dos projetos teve por objetivo levantar os aspectos que afetam a qualidade e a segurança da moradia. Os projetos e a documentação técnica utilizados na análise foram fornecidos pelas empresas proponentes dos SCIs. Os critérios analisados na ficha de verificação dos projetos seguiram a estrutura: desempenho lumínico, desempenho acústico, desempenho térmico, funcionalidade, desempenho contra incêndio, durabilidade, vida útil e desempenho estrutural (FINANCIADORA..., 2012; MENDES et al., 2017).

A estrutura do roteiro de manutenção foi embasada na NBR 14037 (ABNT, 2011) e na NBR 5674 (ABNT, 2012a), as quais tratam, respectivamente, das diretrizes para elaboração de manual de uso, operação e manutenção das edificações e dos requisitos para a elaboração e apresentação de conteúdo, da manutenção de edificações e dos requisitos para o sistema de gestão da manutenção. Para a verificação do "roteiro de manutenção" utilizaram-se os dados contidos no manual de uso, operação e manutenção (manual dos proprietários de ambos os casos), e o programa de manutenção disponibilizado pelas empresas proponentes.

A entrevista com o profissional de assistência técnica forneceu dados qualitativos relevantes quanto aos reparos realizados e a prestação de assistência técnica, o que permitiu balizar, de um modo geral, as informações coletadas. $\mathrm{Na}$ análise da entrevista foram considerados os dados relativos aos reparos realizados e à prestação de assistência técnica.

A pesquisa de campo precedeu as análises documentais dos projetos, do manual de operação, uso e manutenção, assim como o programa de manutenção. As aplicações dos instrumentos de campo ocorreram por meio da inspeção visual, e o protocolo relativo aos fatores de desempenho está detalhado em Mendes (2018). Por se tratar de um trabalho de campo, os instrumentos ficha de verificação da obra (in loco) das áreas internas e externas foram aplicados com o objetivo de obter dados sobre os aspectos de desempenho da edificação em uso, demandando o cruzamento dos dados contidos no projeto e nas aferições de campo. A ficha para a avaliação da manutenção das áreas internas e externas foi aplicada para a detecção de falhas e anomalias decorrentes de procedimentos não conformes de manutenção (ONO et al., 2017a). As fichas e os roteiros foram verificados de acordo com a qualificação da informação, conforme segue: atende, quando o critério é atendido plenamente; ou não atende, quando o critério é atendido parcialmente ou não é atendido.

O último instrumento aplicado foi o questionário ao morador, que possui a seguinte estrutura: caracterização do morador, caracterização da moradia, conforto do usuário da moradia, sistema construtivo, manual de uso, operação e manutenção, e assistência técnica (ONO et al., 2017b). A estrutura do questionário permite identificar a relação entre morador e a moradia executada com o sistema construtivo inovador. Conforme 
Ornstein et al. (2017), a aplicação conjunta dos instrumentos permite obter dados sobre a percepção dos moradores da habitação em relação ao desempenho em uso e a manutenibilidade.

\section{População e amostra}

Para a avaliação das UHs do primeiro conjunto habitacional em sistema concreto-PVC, adotou-se o censo, por possuir apenas 23 UHs, sendo a meta inicial aplicar em 100\% das unidades. Porém, considerando as dificuldades de acesso às moradias, alcançaram-se 18 UHs, o que correspondeu a 78\% da população. Para o conjunto em sistema leve em madeira, a impossibilidade de realização de censo em 66 UHs, por questões de acesso, levou à adoção de uma amostra mínima de 30 UHs, considerando o fato de o conjunto possuir um número inferior a 100 UHs (Tabela 1) (ORNSTEIN; ROMERO, 1992).

Para a aplicação dos questionários aos moradores dos dois conjuntos, adotou-se o censo, pela viabilidade de tempo (uso de aplicativo QuickTapSurvey) e pelo acesso aos moradores no período de pesquisa, além de não requerer acesso à moradia. Porém, não se alcançou a meta de $100 \%$ das tentativas, devido às negativas de moradores em assinar o termo de consentimento livre e esclarecido (TCLE), requerido conforme a aprovação da pesquisa pelo Comitê de Ética. Apesar disso, considera-se que o índice de respostas (87\% e 83\%) foi elevado.

\section{Proposta de otimização dos instrumentos da APO e consulta aos especialistas}

Os instrumentos originais desenvolvidos pelos pesquisadores do Projeto Inovatec (FINEP, 2012) foram testados, sistematicamente, em três conjuntos habitacionais diferenciados pela tecnologia construtiva, sendo apenas o primeiro caso considerado um pré-teste e aplicado no âmbito do Projeto Inovatec, e os outros dois apresentados neste artigo. A aplicação sistemática permitiu verificar que os instrumentos de campo e précampo possuíam um número significativo de itens “não aplicáveis”, necessitando de adequações em todos os instrumentos do método original de APO. A aplicação nos dois conjuntos permitiu confirmar a necessidade de redução de 57\% dos itens, totalizando 304 itens, por não aplicabilidade ou por “não relevância” à avaliação de desempenho em uso com foco no SCI. O método otimizado foi testado por meio do critério de avaliação proposto, e os resultados são apresentados na última seção deste artigo. A Tabela 2 apresenta a proposta de redução para otimizar os instrumentos da APO.

Para aprimorar o método otimizado, em fevereiro de 2018 os instrumentos foram apresentados a dois especialistas: um com formação em arquitetura e urbanismo, experiência em tecnologia da arquitetura, com ênfase em segurança contra incêndio, avaliação de desempenho e acessibilidade, e outro com formação acadêmica em Engenharia Civil, especialista em sistemas construtivos e desempenho de edificações habitacionais. O objetivo da consulta aos especialistas foi discutir e validar a otimização do conteúdo das fichas e do roteiro de avaliação, assim como do critério de avaliação das falhas sistemáticas. Os especialistas confirmaram a existência de itens considerados não aplicáveis à avaliação de desempenho com foco no SCI.

A Tabela 2 apresenta a proposta de redução do número de itens para otimizar o conteúdo dos instrumentos da APO.

Tabela 1 - População e amostra

\begin{tabular}{|c|c|c|c|}
\hline $\begin{array}{l}\text { TECNOLOGIA } \\
\text { CONSTRUTIVA } \\
\text { (Total de UH) }\end{array}$ & $\begin{array}{c}\text { APLICAÇÃO DA } \\
\text { FICHA DE } \\
\text { VERIFICAÇÃO } \\
\text { DA OBRA (in loco) }\end{array}$ & $\begin{array}{l}\text { APLICAÇÃO DA } \\
\text { FICHA DE } \\
\text { AVALIAÇÃO DA } \\
\text { MANUTENÇÃO } \\
\text { (in loco) } \\
\end{array}$ & $\begin{array}{c}\text { APLICAÇÃO DE } \\
\text { QUESTIONÁRIO AOS } \\
\text { MORADORES } \\
\text { (Aprovação pelo Comitê de } \\
\text { Ética em } 5 \text { de agosto de 2016) }\end{array}$ \\
\hline $\begin{array}{l}\text { Painéis de } \\
\text { concreto-PVC } \\
\text { (23 UHs) } \\
\end{array}$ & $\begin{array}{l}18 \text { UHs (78\% censo) } \\
\text { (08 a } 10 \text { de junho de } \\
2016)\end{array}$ & $\begin{array}{l}18 \text { UHs (78\% censo) } \\
\text { (08 a } 10 \text { de junho de } \\
2016)\end{array}$ & $\begin{array}{l}20 \text { moradores ( } 87 \% \text { censo) } \\
\text { (07 e } 08 \text { de setembro de } 2016)\end{array}$ \\
\hline $\begin{array}{l}\text { Painéis leves em } \\
\text { madeira } \\
\text { (66 UHs) }\end{array}$ & $\begin{array}{l}30 \text { UHs } \\
\text { (amostra aleatória) } \\
\text { (25 a } 27 \text { de agosto de } \\
2016)\end{array}$ & $\begin{array}{l}30 \text { UHs } \\
\text { (amostra aleatória) } \\
\text { (25 a } 27 \text { de agosto de } \\
2016 \text { ) }\end{array}$ & $\begin{array}{l}55 \text { moradores ( } 83 \% \text { censo) } \\
\text { ( } 25 \text { a } 27 \text { de agosto de } 2016 \text { e } \\
09 \text { a } 10 \text { de setembro de } 2016 \text { ) }\end{array}$ \\
\hline
\end{tabular}

Nota: Legenda: UHs - Unidades habitacionais. 
Tabela 2 - Proposta de otimização dos instrumentos

\begin{tabular}{c|c|c}
\hline $\begin{array}{c}\text { INSTRUMENTO NO ÂMBITO DO } \\
\text { INOVATEC (FINEP, 2012) }\end{array}$ & $\begin{array}{c}\text { TOTAL DE ITENS } \\
\text { POR INSTRUMENTO }\end{array}$ & $\begin{array}{c}\text { PROPOSTA DE } \\
\text { REDUÇÃO DOS } \\
\text { ITENS }\end{array}$ \\
\hline $\begin{array}{c}\text { Ficha de verificação do projeto } \\
\text { Roteiro para a avaliação do manual de uso, } \\
\text { operação e manutenção }\end{array}$ & $69(100 \%)$ & $27(39 \%)$ \\
\hline Ficha de verificação da obra (in loco) & $185(100 \%)$ & $134(72 \%)$ \\
\hline Ficha para a avaliação da manutenção (in loco) & $72(100 \%)$ & $36(50 \%)$ \\
\hline Questionário ao morador & $112(100 \%)$ & $52(46 \%)$ \\
\hline Total & $95(100 \%)$ & $55(58 \%)$ \\
\hline
\end{tabular}

Fonte: Mendes (2018), adaptado de Financiadora de Estudos e Projetos (2012).

\section{Proposta de critério para avaliação dos resultados da APO}

A proposta de critério para a avaliação dos resultados de APO contempla a otimização dos instrumentos originais e foi seguida da atribuição de relevância aos fatores de desempenho à luz da NBR 15575 (ABNT, 2013), assim como da atribuição de pesos e do limite de tolerância aplicados às falhas sistemáticas.

A atribuição de relevância se aplica apenas aos critérios da "ficha de verificação da obra (in loco)" e da "ficha para a avaliação da manutenção” do SCI. A proposta foi realizada a partir dos requisitos, dos usuários, relativos à segurança, habitabilidade e sustentabilidade. Para os fatores relacionados à segurança, atribuiu-se a relevância de nível alto por estarem vinculados à segurança estrutural, segurança contra incêndio e por poderem comprometer a segurança dos usuários súbita ou imediatamente. Os requisitos da habitabilidade foram considerados de relevância nível médio, tendo em vista que questões como o conforto térmico, acústico e lumínico, funcionalidade e acessibilidade, podem comprometer o sistema construtivo e a integridade de forma progressiva. Aos requisitos de sustentabilidade que se referem a durabilidade e manutenibilidade, foi atribuída a relevância de nível baixo, pois dizem respeito aos aspectos de manutenção em longo prazo. Na Tabela 3 apresentam-se os pesos para o limite de tolerância para falhas. Os resultados dos percentuais de 10\% para itens com relevância alta (fator segurança), 20\% para a relevância média (fator habitabilidade) e 30\% para a relevância baixa (durabilidade e manutenibilidade) se justificam por testes anteriores, que não geraram resultados que diferenciassem eventuais falhas sistemáticas de problemas isolados da moradia. A utilização de uma escala de valores de $10 \%$ foi utilizada devido ao fato de o fator limitante da amostra ser inferior a 100 UHs.

A partir do peso atribuído às falhas, chegou-se aos valores que representam a importância do item analisado. Estes foram classificados de forma decrescente e representados por gráfico de barras. Tais valores permitiram identificar os itens prioritários da avaliação e que devem ser considerados em uma eventual reavaliação por parte da ITA. O critério de avaliação aplicado às falhas sistemáticas encontra-se detalhado em Mendes (2018).

Tabela 3 - Atribuição de relevância aos fatores de desempenho

\begin{tabular}{c|c|c|c}
\hline $\begin{array}{c}\text { REQUISITOS DOS } \\
\text { USUÁRIOS }\end{array}$ & SEGURANÇA & HABITABILIDADE & SUSTENTABILIDADE \\
\hline RELEVÂNCIA & ALTA & MÉDIA & BAIXA \\
\hline PESO & PESO 3 & PESO 2 & PESO 1 \\
FATORES & $\begin{array}{c}\text { Segurança estrutural } \\
\text { Segurança contrafogo } \\
\text { Segurança no uso e } \\
\text { operação }\end{array}$ & $\begin{array}{c}\text { Estanqueidade } \\
\text { Conforto Térmico } \\
\text { Conforto Acústico } \\
\text { Conforto Lumínico } \\
\text { Funcionalidade e } \\
\text { Acessibilidade }\end{array}$ & $\begin{array}{c}\text { Durabilidade e } \\
\text { Manutenibilidade }\end{array}$ \\
\hline $\begin{array}{c}\text { LIMITE DE } \\
\text { TOLERÂNCIAS }\end{array}$ & $\begin{array}{c}\text { 20\% } \\
\text { PARA AS FALHAS } \\
\text { SISTEMATICAS }\end{array}$ & $10 \%$ & $30 \%$ \\
\hline
\end{tabular}

Fonte: Mendes (2018). 


\section{Resultados do desempenho em uso dos SCls a partir do método otimizado}

A seguir apresentam-se os resultados das APOs relativas às habitações construídas em concreto-PVC e no sistema leve em madeira, a partir dos instrumentos otimizados: avaliação do projeto, manual de uso, operação e manutenção, avaliação da obra (in loco) e da manutenção (in loco). O critério avaliativo das falhas sistemáticas foi aplicado aos instrumentos in loco, o que possibilitou neste artigo avaliar o desempenho, em uso, dos SCIs, e recomendar às ITAs os itens prioritários em futuras reavaliações para os dois casos.

\section{Avaliação do projeto}

A média geral dos itens atendidos aumentou nos dois casos quando comparados ao método otimizado e ao instrumento original, em relação aos critérios durabilidade, vida útil e desempenho estrutural, o que se deve à retirada dos itens que não se aplicavam à habitação térrea isolada ou geminada no lote. Outra contribuição da revisão do método otimizado foi quanto à separação dos itens que se referem ao manual de uso e aos itens que avaliam os detalhes de projeto, o que indica muitas possibilidades de aprimoramento nesses quesitos. Conforme a Tabela 4, os projetos dos dois sistemas construtivos demonstram possibilidades de melhorias nos critérios de segurança contra incêndio, desempenho lumínico, detalhes de projeto, manual de manutenção e acessibilidade.

O critério durabilidade, vida útil e desempenho estrutural foi considerado satisfatório para o projeto da habitação em sistema leve de madeira, enquanto para o sistema concreto-PVC os resultados indicaram a possibilidade de melhorias para 33\% dos itens relacionados ao projeto.

\section{Avaliação do manual de uso, operação e manutenção}

As avaliações dos dois manuais indicaram a necessidade de incremento das informações sobre os fornecedores, a operação e a ligação de equipamentos (Tabela 5). Recomenda-se às empresas construtoras complementarem as informações sobre a atualização do manual, a flexibilidade do projeto e a adaptabilidade dos sistemas construtivos. Além disso, a avaliação permitiu indicar as necessidades de melhorias nos dois programas de manutenção quanto aos quesitos de periodicidade e procedimentos para manutenção. A avaliação do memorial descritivo dos projetos foi positiva no que diz respeito à descrição dos sistemas construtivos, cargas máximas, recomendações de limpeza, uso e acesso para manutenção. Ressalta-se que as informações sobre garantias e assistência técnica também foram avaliadas satisfatoriamente.

Tabela 4 - Avaliação dos projetos

\begin{tabular}{|c|c|c|c|c|}
\hline \multicolumn{5}{|c|}{ AVALIAÇÃO DO PROJETO } \\
\hline $\begin{array}{l}\text { SISTEMA CONSTRUTIVO } \\
\text { INOVADOR }\end{array}$ & \multicolumn{2}{|c|}{ SISTEMA CONCRETO-PVC } & \multicolumn{2}{|c|}{$\begin{array}{l}\text { SISTEMA LEVE EM } \\
\text { MADEIRA }\end{array}$} \\
\hline CRITÉRIOS & $\begin{array}{c}\text { ATENDE } \\
(\%)\end{array}$ & $\begin{array}{c}\text { NÃO } \\
\text { ATENDE } \\
(\%)\end{array}$ & $\begin{array}{c}\text { ATENDE } \\
(\%)\end{array}$ & $\begin{array}{c}\text { NÃO } \\
\text { ATENDE } \\
(\%)\end{array}$ \\
\hline Desempenho térmico & $5(100 \%)$ & 0 & $5(100 \%)$ & 0 \\
\hline Segurança contra incêndio & $7(78 \%)$ & $2(22 \%)$ & $7(78 \%)$ & $2(22 \%)$ \\
\hline Funcionalidade & $7(70 \%)$ & $3(30 \%)$ & $9(90 \%)$ & $1(10 \%)$ \\
\hline $\begin{array}{l}\text { Durabilidade, vida útil e } \\
\text { desempenho estrutural }\end{array}$ & $4(67 \%)$ & $2(33 \%)$ & $6(100 \%)$ & 0 \\
\hline Desempenho lumínico & $1(50 \%)$ & $1(50 \%)$ & $1(50 \%)$ & $1(50 \%)$ \\
\hline $\begin{array}{l}\text { Manual de operação, uso e } \\
\text { manutenção }\end{array}$ & $1(33 \%)$ & $2(67 \%)$ & $2(67 \%)$ & $1(33 \%)$ \\
\hline Detalhes de projeto & $1(25 \%)$ & $3(75 \%)$ & $4(80 \%)$ & $1(20 \%)$ \\
\hline Acessibilidade & 0 & $2(100 \%)$ & $1(50 \%)$ & $1(50 \%)$ \\
\hline MÉDIA & $\begin{array}{c}26(63 \%) \\
\text { Média } \\
41 \text { itens }\end{array}$ & $\begin{array}{c}15(37 \%) \\
\text { Média } \\
41 \text { itens }\end{array}$ & $\begin{array}{c}35(83 \%) \\
\text { Média } \\
42 \text { itens }\end{array}$ & $\begin{array}{c}7(17 \%) \\
\text { Média } \\
42 \text { itens }\end{array}$ \\
\hline
\end{tabular}

Fonte: adaptado de Financiadora de Estudos e Projetos (2012) e Mendes (2018). 
Contrapondo as verificações positivas dos manuais, com a aplicação dos questionários aos moradores, verificou-se que estes não realizam a leitura do manual do proprietário, podendo-se inferir que haverá ocorrência de procedimentos de manutenção não conformes, ou mesmo inexistentes.

Na proposta de otimização, os requisitos de flexibilidade e adaptabilidade do projeto passam a ter importância, considerando que os moradores realizam modificações da casa e os resultados da avaliação do manual de uso, operação e manutenção foram insatisfatórios (Tabela 5).

Tabela 5 - Manual de uso, operação e manutenção

\begin{tabular}{|c|c|c|c|c|}
\hline \multicolumn{5}{|c|}{ AVALIAÇÃO DO MANUAL DE USO, OPERAÇÃO E MANUTENÇÃO } \\
\hline $\begin{array}{l}\text { SISTEMA CONSTRUTIVO } \\
\text { INOVADOR } \\
\end{array}$ & \multicolumn{2}{|c|}{$\begin{array}{c}\text { SISTEMA } \\
\text { CONCRETO-PVC } \\
\end{array}$} & \multicolumn{2}{|c|}{$\begin{array}{c}\text { SISTEMA LEVE EM } \\
\text { MADEIRA } \\
\end{array}$} \\
\hline $\begin{array}{l}\text { ESTRUTURA DO MANUAL DE USO, } \\
\text { OPERAÇÃO E MANUTENÇÃO }\end{array}$ & $\begin{array}{l}\text { ATENDE } \\
(\%)\end{array}$ & $\begin{array}{c}\text { NÃO } \\
\text { ATENDE } \\
(\%) \\
\end{array}$ & $\begin{array}{l}\text { ATENDE } \\
(\%)\end{array}$ & $\begin{array}{c}\text { NÃO } \\
\text { ATENDE } \\
(\%) \\
\end{array}$ \\
\hline Apresentação, introdução e definições & $1(33 \%)$ & $2(67 \%)$ & $3(100 \%)$ & 0 \\
\hline Garantias e assistência técnica & $3(100 \%)$ & 0 & $3(100 \%)$ & 0 \\
\hline Requisitos mínimos para manual & $3(100 \%)$ & 0 & $3(100 \%)$ & 0 \\
\hline $\begin{array}{l}\text { Informações sobre fornecedores, projetistas e } \\
\text { serviços públicos }\end{array}$ & $1(33 \%)$ & $2(67 \%)$ & $2(67 \%)$ & $1(33 \%)$ \\
\hline $\begin{array}{l}\text { Segurança estrutural, contra incêndio e no uso } \\
\text { e ocupação }\end{array}$ & $3(50 \%)$ & $3(50 \%)$ & $3(50 \%)$ & $3(50 \%)$ \\
\hline Operação de equipamentos e suas ligações & $1(50 \%)$ & $1(50 \%)$ & $1(50 \%)$ & $1(50 \%)$ \\
\hline Meio ambiente e sustentabilidade & 0 & $1(100 \%)$ & 0 & $1(100 \%)$ \\
\hline Atualização do manual & 0 & $1(100 \%)$ & 0 & $1(100 \%)$ \\
\hline Flexibilidade & 0 & $8(100 \%)$ & 0 & $8(100 \%)$ \\
\hline $\begin{array}{l}\text { Adaptabilidade do sistema } \\
\text { construtivo/produto inovador a recursos } \\
\text { regionais e sistemas tradicionais }\end{array}$ & 0 & $5(100 \%)$ & 0 & 5 (100\%) \\
\hline DOCUMENTAÇÃO TÉCNICA & $\begin{array}{l}\text { ATENDE } \\
(\%)\end{array}$ & $\begin{array}{c}\text { NÃO } \\
\text { ATENDE } \\
(\%) \\
\end{array}$ & $\begin{array}{l}\text { ATENDE } \\
\quad(\%)\end{array}$ & $\begin{array}{c}\text { NÃO } \\
\text { ATENDE } \\
(\%) \\
\end{array}$ \\
\hline Orientações para a adaptabilidade do projeto & $1(50 \%)$ & $1(50 \%)$ & 0 & $2(100 \%)$ \\
\hline $\begin{array}{l}\text { Apresentação de detalhes técnicos das } \\
\text { interfaces do SCI e demais sistemas }\end{array}$ & 0 & $1(100 \%)$ & $1(100 \%)$ & 0 \\
\hline Verificação da flexibilidade do projeto & 0 & $2(100 \%)$ & 0 & $2(100 \%)$ \\
\hline MEMORIAL DESCRITIVO & $\begin{array}{l}\text { ATENDE } \\
(\%)\end{array}$ & $\begin{array}{c}\text { NÃO } \\
\text { ATENDE } \\
(\%) \\
\end{array}$ & $\begin{array}{l}\text { ATENDE } \\
(\%)\end{array}$ & $\begin{array}{l}\text { NÃO } \\
\text { ATENDE } \\
(\%)\end{array}$ \\
\hline $\begin{array}{l}\text { Informações sobre propriedades do SCI, } \\
\text { cargas máximas, descrição dos sistemas } \\
\text { construtivos complementares, instruções de } \\
\text { uso, recomendações de limpeza e } \\
\text { recomendações para acesso de manutenção e } \\
\text { limpeza }\end{array}$ & $6(75 \%)$ & $2(25 \%)$ & $8(100 \%)$ & 0 \\
\hline PROGRAMA DE MANUTENÇÃO & $\begin{array}{l}\text { ATENDE } \\
(\%)\end{array}$ & $\begin{array}{c}\text { NÃO } \\
\text { ATENDE } \\
(\%) \\
\end{array}$ & $\begin{array}{l}\text { ATENDE } \\
(\%)\end{array}$ & $\begin{array}{l}\text { NÃO } \\
\text { ATENDE } \\
(\%) \\
\end{array}$ \\
\hline $\begin{array}{l}\text { Apresentação do programa com a } \\
\text { periodicidade das manutenções, informações } \\
\text { sobre procedimentos e roteiros para } \\
\text { manutenção e periodicidade de realização de } \\
\text { laudos por profissionais habilitados }\end{array}$ & $2(67 \%)$ & $1(33 \%)$ & $2(67 \%)$ & $1(33 \%)$ \\
\hline MÉDIA & $\begin{array}{c}21 \\
(41 \%) \\
\end{array}$ & $\begin{array}{c}30 \\
(59 \%) \\
\end{array}$ & $26(49 \%)$ & $\begin{array}{c}25 \\
(51 \%) \\
\end{array}$ \\
\hline
\end{tabular}

Fonte: adaptado de Financiadora de Estudos e Projetos (2012) e Mendes (2018). 


\section{Avaliação da obra (in loco)}

As avaliações das obras indicam que os fatores internos e externos da estanqueidade podem afetar a durabilidade e a vida útil do sistema construtivo, uma vez que as ligações das paredes com a fundação, nos dois casos, são formadas por ancoragens metálicas. No caso do sistema construtivo de perfis leves em madeira, apesar do uso de parafusos galvanizados e de um sistema de impermeabilização para proteção dos painéis, verificou-se a exposição das UHs à umidade no piso e na base das paredes, o que é um fator de risco à durabilidade do SCI.

Na avaliação do critério de segurança contra incêndio foi possível identificar falta de local apropriado para o armazenamento do botijão (Tabela 6). No caso do sistema leve em madeira não é permitido embutimento das instalações de gás no painel de vedação, e por isso o risco fica evidente, uma vez que o botijão é armazenado no interior da residência com uma ventilação natural precária. Ademais, verificou-se nas APOs que os moradores dos dois casos obstruem as janelas da cozinha com móveis. Tais situações reforçam a necessidade de uma avaliação em uso do SCI.

Uma das contribuições do método foi a separação dos itens de desempenho estrutural e da durabilidade, permitindo identificar diferenças de atendimento aos critérios, pois o desempenho estrutural atende de $85 \%$ a $96 \%$, enquanto a durabilidade atende de $50 \%$ a $78 \%$. (Tabela 6). Ao se aplicar o critério do limite, verificouse que há a necessidade de as ITAs reavaliarem os dois sistemas em relação às deformações na estrutura da cobertura do sistema concreto-PVC e as fissuras presentes nas juntas do sistema leve em madeira. No segundo caso, é previsto no manual do proprietário a manutenção nas juntas e, portanto, o desempenho estrutural foi considerado satisfatório.

A Figura 4 apresenta a classificação dos itens recomendados para a reavaliação por parte da ITA. Os itens com o maior valor numérico, de 1 a 3, representam os problemas significativos pela relação frequência e peso, sendo o peso (1) indicado para a relevância baixa (fator de desempenho - sustentabilidade - durabilidade e manutenibilidade); peso (2) indicado para a relevância média (fator de desempenho - habitabilidade) e peso (3) com indicação para o nível alto de relevância (fator de desempenho - segurança). A partir dos resultados, verificou-se que há itens que se aproximam do valor 3,0 nos dois casos, o que demonstra que os problemas mais significativos estão relacionados ao fator de desempenho - segurança contra incêndio. A faixa entre 1 e 2, nos dois sistemas construtivos, confirmam que o fator de desempenho - estanqueidade (relevância média) é o segundo aspecto mais importante pela sua recorrência em problemas de umidade na base das paredes e de umidade no piso interno, nas áreas externas e nas internas (Figura 4). Considera-se que as falhas sistemáticas que se referem à umidade na base das paredes e no piso interno, decorrentes no caso do concreto-PVC, devemse à falta de calçada no entorno da edificação e, no segundo caso, ao caimento inadequado da pavimentação externa e a inexistência de drenagem do terreno. Nos dois casos há a não observância dos procedimentos de manutenção por parte dos moradores, agravada no sistema concreto-PVC pela falta de assistência técnica.

Tabela 6 - Avaliação da obra

\begin{tabular}{|c|c|c|c|c|}
\hline \multicolumn{5}{|c|}{ AVALIAÇÃO DA OBRA (in loco) } \\
\hline $\begin{array}{l}\text { SISTEMA CONSTRUTIVO } \\
\text { INOVADOR }\end{array}$ & \multicolumn{2}{|c|}{ SISTEMA CONCRETO-PVC } & \multicolumn{2}{|c|}{$\begin{array}{l}\text { SISTEMA LEVE EM } \\
\text { MADEIRA }\end{array}$} \\
\hline $\begin{array}{c}\text { CRITÉRIOS } \\
\text { ÁREAS INTERNAS }\end{array}$ & $\begin{array}{l}\text { ATENDE } \\
(\%)\end{array}$ & $\begin{array}{c}\text { NÃO } \\
\text { ATENDE (\%) }\end{array}$ & $\begin{array}{l}\text { ATENDE } \\
(\%)\end{array}$ & $\begin{array}{c}\text { NÃO ATENDE } \\
(\%)\end{array}$ \\
\hline Desempenho estrutural & $95 \%$ & $5 \%$ & $96 \%$ & $4 \%$ \\
\hline $\begin{array}{c}\text { Durabilidade e vida útil - } \\
\text { Estanqueidade }\end{array}$ & $78 \%$ & $22 \%$ & $66 \%$ & $34 \%$ \\
\hline Funcionalidade e acessibilidade & $60 \%$ & $40 \%$ & $80 \%$ & $20 \%$ \\
\hline Segurança contra incêndio & $3 \%$ & $97 \%$ & $2 \%$ & $98 \%$ \\
\hline MÉDIA & $59 \%$ & $41 \%$ & $61 \%$ & $39 \%$ \\
\hline $\begin{array}{c}\text { CRITÉRIO } \\
\text { ÁREAS EXTERNAS } \\
\end{array}$ & $\begin{array}{c}\text { ATENDE } \\
(\%) \\
\end{array}$ & $\begin{array}{c}\text { NÃO } \\
\text { ATENDE (\%) } \\
\end{array}$ & $\begin{array}{c}\text { ATENDE } \\
(\%) \\
\end{array}$ & $\begin{array}{c}\text { NÃO ATENDE } \\
(\%)\end{array}$ \\
\hline Desempenho estrutural & $86 \%$ & $14 \%$ & $85 \%$ & $15 \%$ \\
\hline $\begin{array}{c}\text { Durabilidade e vida útil - } \\
\text { Estanqueidade }\end{array}$ & $50 \%$ & $50 \%$ & $65 \%$ & $35 \%$ \\
\hline MÉDIA & $68 \%$ & $32 \%$ & $75 \%$ & $25 \%$ \\
\hline
\end{tabular}

Fonte: Mendes (2018), adaptado de Financiadora de Estudos e Projetos (2012). 
Figura 4 - Importância dos itens não atendidos do sistema concreto-PVC

\section{Verificação da obra - Áreas internas e externas Importância dos itens não atendidos - Sisjkjtema Concreto-PVC}

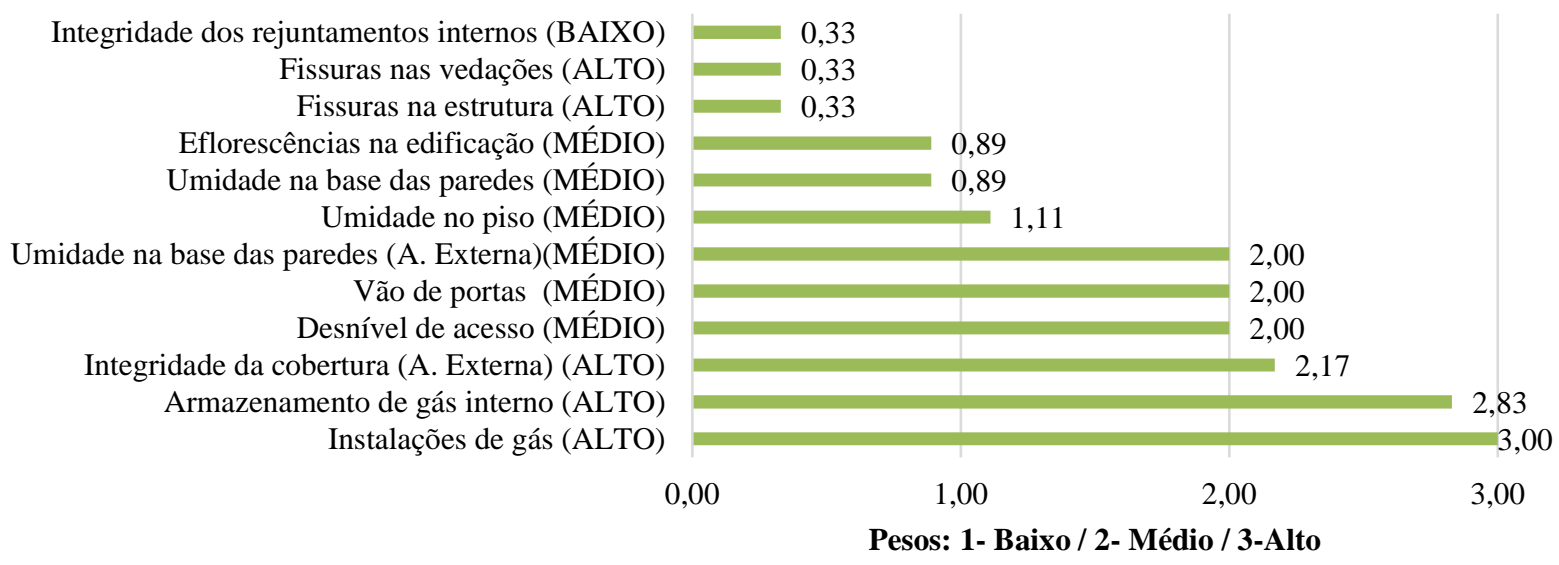

Fonte: Mendes (2018).

No caso do sistema construtivo leve em madeira, os problemas de estanqueidade na moradia devem ser considerados prioritários, pois a partir da inspeção predial identificou-se a presença de umidade nos revestimentos cerâmicos dos painéis de vedação da cozinha e banheiros. Como esse é um sistema que apresenta detalhes de projeto das ligações das paredes com a fundação, com ênfase na impermeabilização, recomenda-se maior atenção na execução e na manutenção. A partir da inspeção predial também se identificou a não conformidade na integridade dos selantes das juntas, devido à falta de manutenção por parte dos moradores, o que agrava o problema.

Sobre o item "fissuras nas vedações", avaliado nos dois casos e indicado para reavaliação pela ITA, este não chega a atingir o valor numérico significativo do respectivo peso (3) para o fator segurança estrutural. No caso do painel leve em madeira, a falta de integridade das juntas externas expõe à umidade a camada interna do painel autoportante. As fissuras presentes nas juntas externas desses painéis têm maior relevância estética do que estrutural, mas também interferem na durabilidade do sistema (Figura 5).

\section{Avaliação da manutenção (in loco)}

As avaliações da manutenibilidade dos dois sistemas mostraram que os problemas estão relacionados aos procedimentos de manutenção (in loco) e estão descritos na Tabela 7.

Os pontos críticos identificados nas avaliações das manutenções encontram-se nos revestimentos de parede, esquadrias de alumínio, revestimento de piso, cobertura, fachadas e pavimentação. No caso específico do sistema concreto-PVC, sobressaem os problemas de interface com o forro e as esquadrias. No sistema leve em madeira destaca-se que os pontos críticos se encontram nas interfaces dos SCIs com a cobertura e revestimento de piso interno. Em ambos os casos a fachada e a pavimentação externa requerem maiores cuidados nas manutenções. De um modo geral, a avaliação da manutenção indicou o fator estanqueidade dos sistemas convencionais como o mais abordado, seguido pelo fator segurança. Os sinais de infiltração foram considerados como falhas sistemáticas (Figuras 6 e 7).

A Figura 6 apresenta a classificação dos itens recomendados para a reavaliação da ITA. Os itens relacionados ao fator da segurança do sistema concreto-PVC considerados como os mais significativos foram as deformações no forro. Os itens identificados no fator estanqueidade são: calafetação das esquadrias, ausência de acessórios na cobertura, umidade na pavimentação externa, infiltração e manchas no piso. Os itens de relevância alta, mais significativos, são: funcionamento das esquadrias de madeira e de alumínio, fissuras no forro e fixação de telhas. Destaca-se nesse critério avaliativo que um item de relevância média pode assumir maior importância que um de relevância alta, sendo que o peso dado à frequência do item não atendido é o que determina esse resultado. 
No caso do sistema concreto-PVC, o critério durabilidade pode ser afetado progressivamente com os problemas de estanqueidade. Outro ponto a ser observado é em relação às deformações presentes na estrutura, as quais podem comprometer o funcionamento das esquadrias, do forro e da cobertura (Figura 6).

Figura 5 - Importância dos itens não atendidos do sistema leve em madeira

Verificação da obra - Áreas internas e externas Importância dos itens não atendidos - Sistema Leve em Madeira

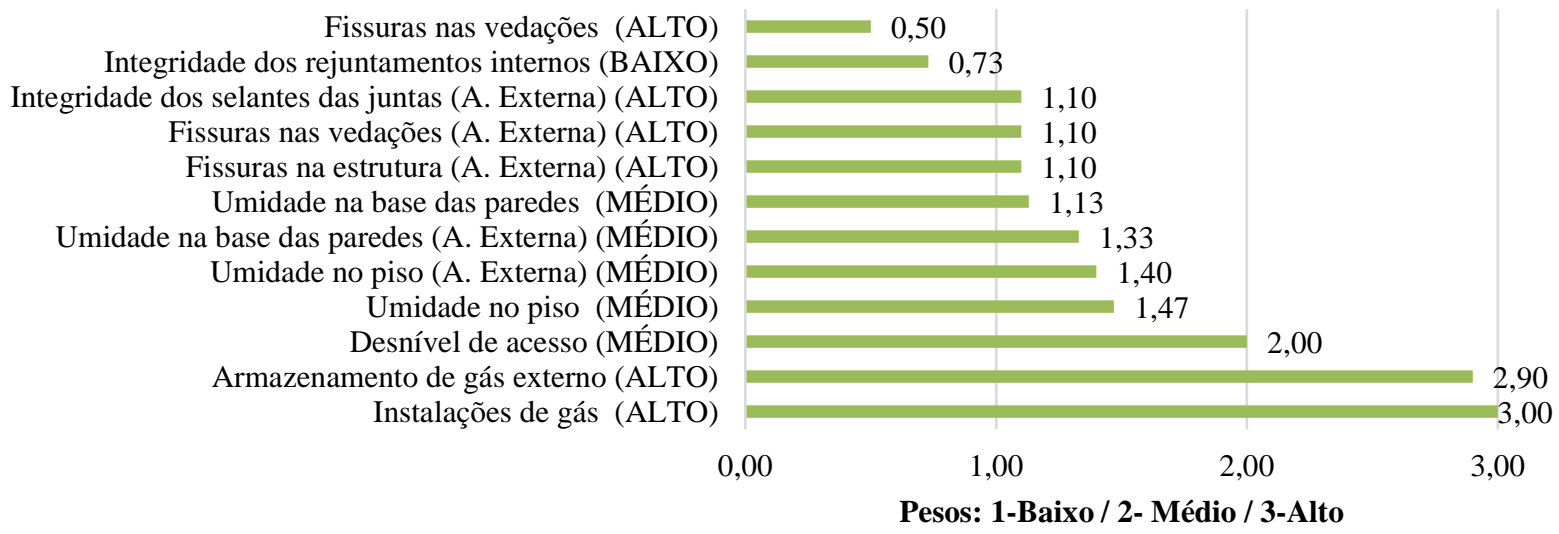

Fonte: Mendes (2018).

Tabela 7 - Avaliação da manutenção

\begin{tabular}{|c|c|c|c|c|}
\hline \multicolumn{5}{|c|}{ AVALIAÇÃO DA MANUTENÇÃO (in loco) } \\
\hline \multirow{2}{*}{$\begin{array}{c}\text { SISTEMA CONSTRUTIVO } \\
\text { INOVADOR } \\
\text { ÁREAS INTERNAS }\end{array}$} & \multicolumn{2}{|c|}{ SISTEMA CONCRETO-PVC } & \multicolumn{2}{|c|}{$\begin{array}{c}\text { SISTEMA LEVE EM } \\
\text { MADEIRA }\end{array}$} \\
\hline & $\begin{array}{l}\text { ATENDE } \\
(\%)\end{array}$ & $\begin{array}{c}\text { NÃO } \\
\text { ATENDE (\%) }\end{array}$ & $\begin{array}{l}\text { ATENDE } \\
(\%)\end{array}$ & $\begin{array}{c}\text { NÃO } \\
\text { ATENDE } \\
(\%)\end{array}$ \\
\hline Estruturas & $89 \%$ & $11 \%$ & $95 \%$ & $5 \%$ \\
\hline Paredes e painéis de vedação & $83 \%$ & $17 \%$ & $90 \%$ & $10 \%$ \\
\hline $\begin{array}{l}\text { Revestimentos de paredes (áreas } \\
\text { molhadas e não molhadas) }\end{array}$ & $72 \%$ & $28 \%$ & $76 \%$ & $24 \%$ \\
\hline Instalações hidrossanitárias & $96 \%$ & $4 \%$ & $83 \%$ & $17 \%$ \\
\hline Instalações elétricas & $69 \%$ & $31 \%$ & $88 \%$ & $12 \%$ \\
\hline Esquadrias (alumínio) (portas e janelas) & $64 \%$ & $36 \%$ & $76 \%$ & $24 \%$ \\
\hline Revestimento de piso & $60 \%$ & $40 \%$ & $69 \%$ & $31 \%$ \\
\hline Forro (pintura e estrutura) & $52 \%$ & $48 \%$ & $89 \%$ & $11 \%$ \\
\hline Esquadrias de madeira (portas) & $38 \%$ & $62 \%$ & $91 \%$ & $9 \%$ \\
\hline MÉDIA & $69 \%$ & $31 \%$ & $84 \%$ & $16 \%$ \\
\hline ÁREAS EXTERNAS & $\begin{array}{l}\text { ATENDE } \\
(\%)\end{array}$ & $\begin{array}{c}\text { NÃO } \\
\text { ATENDE (\%) }\end{array}$ & $\begin{array}{l}\text { ATENDE } \\
(\%)\end{array}$ & $\begin{array}{c}\text { NÃO } \\
\text { ATENDE } \\
(\%)\end{array}$ \\
\hline Caixa d’água & $81 \%$ & $19 \%$ & $95 \%$ & $5 \%$ \\
\hline $\begin{array}{l}\text { Cobertura (estrutura, telhas e } \\
\text { acessórios) }\end{array}$ & $58 \%$ & $42 \%$ & $68 \%$ & $32 \%$ \\
\hline $\begin{array}{l}\text { Fachadas (revestimento externo e } \\
\text { juntas) }\end{array}$ & $50 \%$ & $50 \%$ & $66 \%$ & $34 \%$ \\
\hline $\begin{array}{l}\text { Pavimentação - calçadas e acessos } \\
\text { internos ao lote }\end{array}$ & $24 \%$ & $76 \%$ & $74 \%$ & $26 \%$ \\
\hline MÉDIA & $53 \%$ & $47 \%$ & $76 \%$ & $24 \%$ \\
\hline
\end{tabular}

Fonte: Mendes (2018), adaptado de Financiadora de Estudos e Projetos (2012). 
Figura 6 - Importância dos itens não atendidos do sistema concreto-PVC

\section{Avaliação da Manutenção - Áreas internas e externas Importância dos itens não atendidos - Sistema Concreto-PVC}

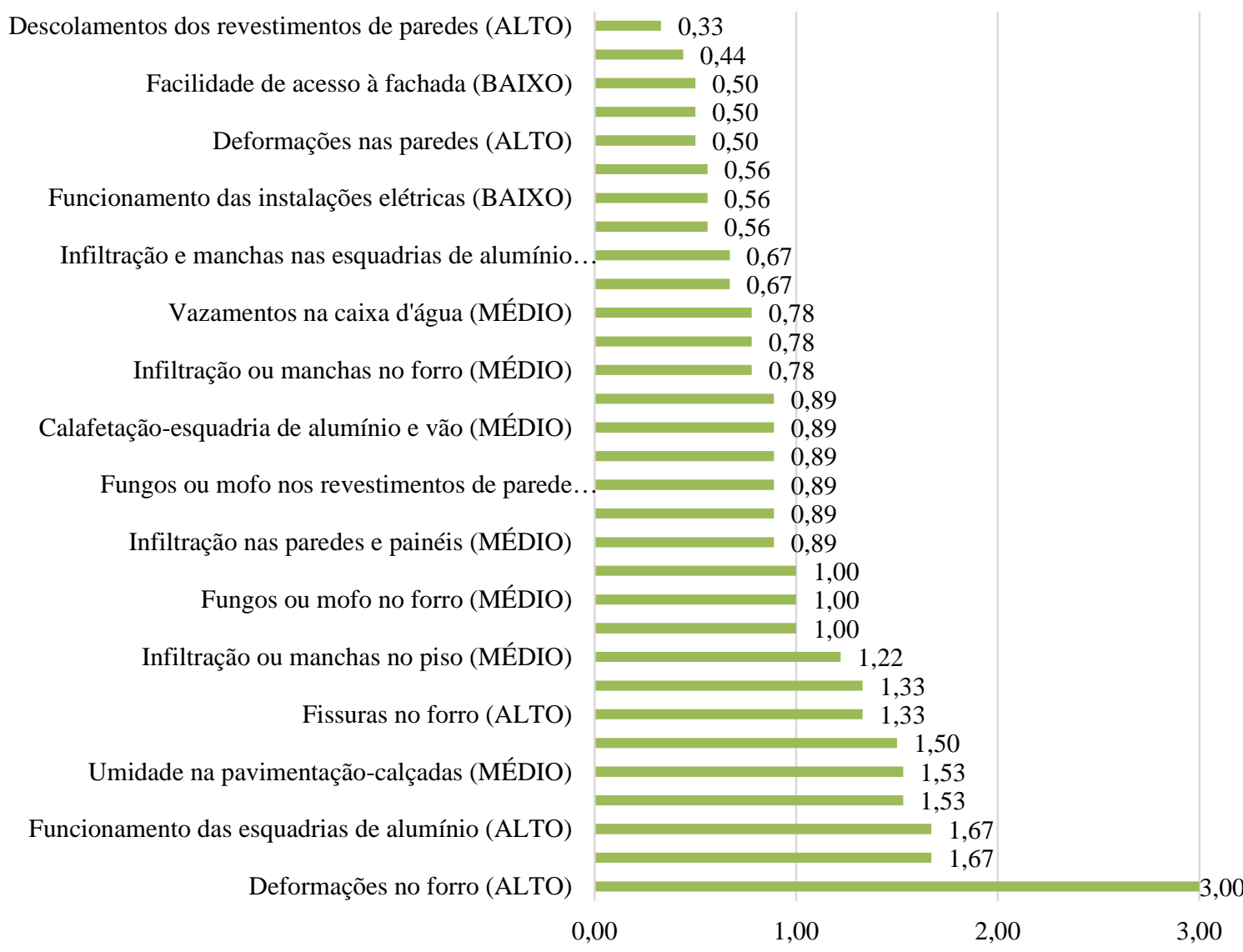

Pesos: 1- Baixo / 2- Médio / 3- Alto

Fonte: Mendes (2018).

A Figura 7 apresenta a classificação dos itens recomendados para a reavaliação da ITA do sistema leve em madeira. O que pode ser observado é que os itens entre os valores 1 e 2 são representados pelos problemas de estanqueidade, decorrentes da ausência de acessórios na cobertura - calhas, infiltração e manchas no piso, infiltração no caixilho de alumínio (esquadria), umidade na pavimentação, infiltração na fachada, infiltração nos revestimentos de paredes e calafetação das esquadrias. Esses itens, pelo valor numérico, têm mais importância que os de relevância alta, tais como as deformações nas esquadrias, fissuras na pavimentação, fissuras na estrutura, fissuras no forro, fissuras nas paredes e painéis externos. Assim como no caso anterior, essas falhas devem ter seu grau de importância ressaltado, visando a melhorias em futuros projetos e adequação dos procedimentos de execução e manutenção.

Os valores dos limites atribuídos aos fatores de desempenho, conforme o critério avaliativo de segurança (10\%), estanqueidade (20\%) e sustentabilidade (durabilidade e manutenibilidade) (30\%), foram considerados adequados na aplicação dos instrumentos "ficha de verificação da obra (in loco)" e "ficha de avaliação da manutenção", pois foram identificadas as falhas sistemáticas a partir desses instrumentos. Aos itens com resultados acima dos limites mencionados indicou-se reavaliação por especialista da área. Essas indicações pontuais podem ser verificadas conforme Mendes (2018).

\section{Recomendações às ITAs}

A aplicação do critério avaliativo, de acordo com o método otimizado, possibilitou classificar os itens analisados em satisfatório ou indicados para a reavaliação por parte das ITAs, conforme a Tabela 8. 
Figura 7 - Importância dos itens não atendidos do sistema leve em madeira

\section{Avaliação da Manutenção - Áreas internas e externas Importância dos itens não atendidos - Sistema Leve em Madeira}

\begin{abstract}
Facilidade de acesso à fachada (BAIXO)
Deformações das esquadrias de alumínio (ALTO)

Fissuras na pavimentação - calçadas (ALTO)

Fissuras nas estruturas (ALTO)

Infiltração nas paredes (MÉDIO)

Funcionamento das esquadrias de madeira (ALTO)

Fissuras no forro (ALTO)

Fissuras nas paredes e painéis (ALTO)

Vazamentos das instalações hidrossanitárias (MÉDIO)

Fungos ou mofo no revestimentos (MÉDIO)

Funcionamento das esquadrias de alumínio (ALTO)

Infiltrações nas instalações hidrossanitárias (MÉDIO)

Presença de fungos ou mofo no piso (MÉDIO)

Fissuras perceptíveis na fachada (ALTO)

Calafetação das esquadrias de alumínio e vão (MÉDIO)

Infiltração ou manchas nos revestimentos (MÉDIO) Infiltração na fachada (MÉDIO)

Umidade na pavimentação - calçadas (MÉDIO)

Infiltração em esquadrias de alumínio (MÉDIO) Infiltração ou manchas no piso (MÉDIO)

Ausência de acessórios na cobertura - calhas (MÉDIO)
\end{abstract}

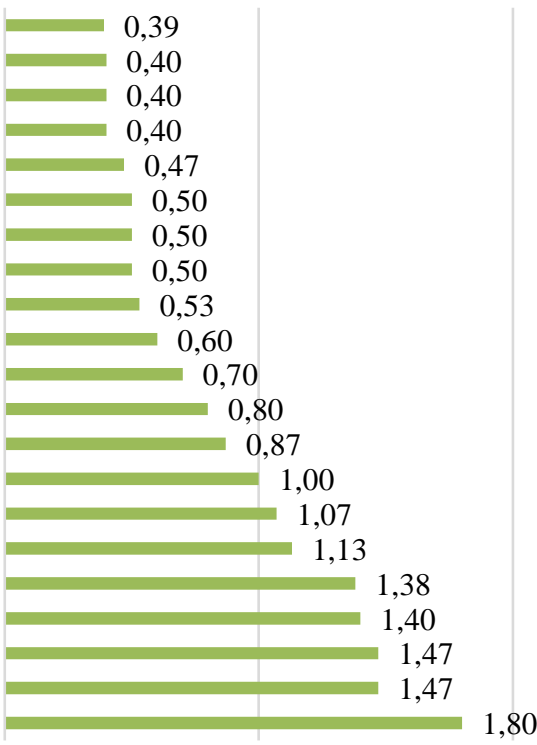

1,00

2,00

Fonte: Mendes (2018).

Tabela 8 - Recomendações às ITAs

\begin{tabular}{c|c|c|c|c|c|c}
\hline $\begin{array}{c}\text { SISTEMAS } \\
\text { CONSTRUTIVOS } \\
\text { INOVADORES }\end{array}$ & \multicolumn{2}{|c|}{$\begin{array}{c}\text { DESEMPENHO } \\
\text { SATISFATÓRIO }\end{array}$} & $\begin{array}{c}\text { ITAs: AVALIAR AS } \\
\text { UNIDADES ONDE } \\
\text { OCORREM OS } \\
\text { PROBLEMAS }\end{array}$ & \multicolumn{2}{c}{$\begin{array}{c}\text { AS ITAs DEVEM } \\
\text { REAVALIAR OS } \\
\text { ITENS INDICADOS }\end{array}$} \\
\hline Ficha de avaliação & $\begin{array}{c}\text { Avaliação } \\
\text { Obra }\end{array}$ & $\begin{array}{c}\text { Avaliação } \\
\text { Manuten- } \\
\text { ção }\end{array}$ & $\begin{array}{c}\text { Avalia- } \\
\text { ção } \\
\text { Obra }\end{array}$ & $\begin{array}{c}\text { Avaliação } \\
\text { Manuten- } \\
\text { ção }\end{array}$ & $\begin{array}{c}\text { Avalia- } \\
\text { ção } \\
\text { Obra }\end{array}$ & $\begin{array}{c}\text { Avaliação } \\
\text { Manuten- } \\
\text { ção }\end{array}$ \\
\hline $\begin{array}{c}\text { Sistema concreto-PVC } \\
\text { (28 itens/50 itens) }\end{array}$ & $\begin{array}{c}15 \text { itens } \\
(54 \%)\end{array}$ & $\begin{array}{c}9 \text { itens } \\
(18 \%)\end{array}$ & $\begin{array}{c}1 \\
(3 \%)\end{array}$ & $\begin{array}{c}9 \text { itens } \\
(18 \%)\end{array}$ & $\begin{array}{c}12 \text { itens } \\
(43 \%)\end{array}$ & $\begin{array}{c}32 \text { itens } \\
(64 \%)\end{array}$ \\
\hline $\begin{array}{c}\text { Sistema } \\
\text { leve em madeira }\end{array}$ & $\begin{array}{c}15 \text { itens } \\
(29 \text { itens/54 itens) }\end{array}$ & $\begin{array}{c}13 \text { itens } \\
(24 \%)\end{array}$ & $\begin{array}{c}2 \text { itens } \\
(7 \%)\end{array}$ & $\begin{array}{c}20 \text { itens } \\
(37 \%)\end{array}$ & $\begin{array}{c}12 \text { itens } \\
(41 \%)\end{array}$ & $\begin{array}{c}21 \text { itens } \\
(39 \%)\end{array}$ \\
\hline
\end{tabular}

Fonte: adaptado de Mendes (2018).

A partir do método proposto recomenda-se às ITAs reavaliarem os aspectos relativos à avaliação da obra e da manutenção (Tabela 8). Nos dois casos apresentados a reavaliação dos itens da avaliação da manutenção (64\% e 39\%) se refere aos subsistemas das áreas internas (esquadrias, forros e revestimentos) e áreas externas (pavimentação e fachada). Destaca-se que a fachada necessita de maior atenção quanto ao comportamento em uso, devido à exposição aos agentes externos e maior suscetibilidade à deterioração dos materiais, inclusive selantes de juntas. A pavimentação desempenha um papel importante para a estanqueidade da base das paredes.

As recomendações às ITAs para a reavaliação dos itens relacionados à avaliação da obra (43\% e 41\%) nos dois casos se referem, em sua maioria, à segurança contra incêndio, funcionalidade e acessibilidade. Nos dois casos a segurança contra incêndio foi prejudicada por aspectos relacionados ao projeto. No sistema leve em 
madeira, recomenda-se não embutir as instalações de gás no interior das paredes por serem vazias. A partir disso, recomenda-se reforçar a indicação que em futuros projetos de HISs sejam previstos, dispositivos para a ventilação permanente do ambiente, se considerado o armazenamento do botijão interno à moradia. Quanto à reavaliação dos itens da obra relacionados à funcionalidade e acessibilidade, os dois casos requerem detalhes projetuais que devem constar no manual de uso, operação e manutenção (manual do proprietário). Esses detalhes, em futuras alterações, auxiliam os profissionais nos procedimentos executivos, visando à qualidade do projeto original, pois se considera que o morador de HIS realiza alterações para adequá-la às suas necessidades. Logo, a falta de adaptabilidade do sistema construtivo pode constituir problemas aos moradores.

As recomendações de reavaliação podem contribuir para o aprimoramento dos SCIs e como exemplo citamse as falhas sistemáticas, identificadas nas interfaces dos sistemas construtivos, que podem decorrer do projeto, da execução ou do uso, operação e manutenção. Dentre as falhas, a falta de estanqueidade foi a que obteve maior frequência, sendo que a continuidade desse problema pode comprometer a habitabilidade da moradia e a durabilidade das vedações que, em geral, deverão atender à vida útil de projeto em até 50 anos. Esse achado confirma a necessidade de monitoramento do comportamento em uso dos SCIs explicitada nos DATecs.

\section{Conclusão}

A aplicação dos instrumentos integrados atendeu ao objetivo proposto, uma vez que propiciou a avaliação de desempenho em uso com foco na identificação das falhas sistemáticas, além de permitir a formulação de recomendações para às ITAs, abrangendo os aspectos de projeto da execução, da manutenção, do uso e da operação. O critério avaliativo proposto e baseado na relevância dos aspectos de desempenho permitiu classificar as falhas sistemáticas com tendência ao comprometimento da durabilidade do sistema, sem mensurar a durabilidade e a vida útil de projeto.

Uma contribuição do método otimizado é que as empresas projetistas/construtores, gestores e as ITAs poderão controlar o comportamento em uso do sistema de vedação, sem ter que recorrer a todos os aspectos de desempenho que são inerentes à moradia, tais como ocorre com o método original. Cita-se como exemplos de falhas sistemáticas obtidas pelo método otimizado: falta de estanqueidade nas interfaces dos sistemas convencionais e o SCI, fissuras localizadas nas juntas e problemas nos caixilhos das esquadrias. Concluiu-se que esses problemas não foram oriundos de deformações da vedação autoportante, o que é positivo na análise do fator de desempenho da segurança estrutural.

A aplicação dos instrumentos otimizados permite afirmar que, em uso, a qualidade do SCI necessita de aprimoramento nas interfaces entre os sistemas, cujas falhas poderiam ser supridas, em parte, pela apresentação de detalhes de projeto, mas que os manuais de uso, operação e manutenção não previram. A partir da análise cruzada dos dados identificaram-se as falhas sistemáticas oriundas do projeto, obra, execução da manutenção, uso e operação. E quando aplicado o critério avaliativo, possibilitou obter a classificação dos itens prioritários de ações de melhorias que, quando recomendados às ITAs, podem nortear as reavaliações que ocorrem para a renovação dos DATecs dos sistemas. Ademais, revisões futuras podem contribuir para complementar as diretrizes e a elaboração de normas dos sistemas de vedações. Esse critério pode ser adotado pelos envolvidos no processo de projeto e, por meio de avaliação técnica, é possível indicar um especialista da área, visando ao aprimoramento do sistema homologado.

Um dos pontos negativos do método otimizado ainda é a quantidade amostral mínima necessária para a confiabilidade dos resultados, que demanda uma equipe de trabalho de campo, devido à quantidade de itens a serem verificados em cada instrumento, fator que gera um extenso banco de dados para ampla análise cruzada das informações. A amostra de ambos os casos pode ser considerada reduzida, e os limites verificados se mostraram adequados, o que valida a proposta para amostras pequenas, inferiores a 100 unidades de moradia. Valores de limites percentuais menores englobariam os casos de problemas pontuais. Os percentuais testados (10\% para o fator segurança, $20 \%$ para o fator habitabilidade - estanqueidade e $30 \%$ para a sustentabilidade - durabilidade e manutenibilidade) não devem ser generalizados. Ressalta-se que a determinação desses valores foi a mais adequada para os estudos de caso, considerando as particularidades de cada empreendimento habitacional e suas tecnologias construtivas.

As considerações sobre a amostragem para a aplicação da ficha de avaliação da obra e da manutenção foram: para a amostra de 30 UHs do sistema leve em madeira foi considerado consistente, por se tratar de uma população de 66 UHs; a amostra de 18 UHs para a aplicação do mesmo instrumento no sistema concreto-PVC foi ainda mais representativo, considerando que a população total é de 23 UHs. Em estudos futuros em população amostral de até 100 UHs, para as vistorias in loco, recomenda-se que sejam selecionadas amostras de no mínimo 20 a 30 UHs. 
No manual de uso, operação e manutenção, a adaptabilidade do SCI deve ser prevista para as futuras intervenções realizadas pelos moradores. Refirma-se também que um manual padronizado pode incorrer em problemas com a segurança, habitabilidade e a durabilidade dos sistemas. Nos dois casos, as proibições quanto às adaptações do projeto da HIS causam a perda de garantia, pois a maioria dos moradores realizou modificações. Nesse sentido, a participação do morador na avaliação de desempenho em uso foi relevante para a aplicação do método da APO, que se mostrou adequado, uma vez que pela vivência com a tecnologia complementou-se a avaliação do especialista, propiciando confirmar os resultados da avaliação técnica.

Uma limitação do método otimizado é que ele não permite mensurar a vida útil de projeto do sistema avaliado, assim como não determina ou confirma a durabilidade e a vida útil do sistema construtivo, mesmo considerando a frequência das falhas sistemáticas.

Quanto aos critérios de desempenho em uso que apresentaram falhas sistemáticas, devem ser reconsideradas, para as futuras revisões das normas de desempenho e elaboração de normas prescritivas dos SCI, as possibilidades de complementação das diretrizes de projeto, dos requisitos do manual de uso, operação e manutenção.

Em geral, afirma-se que os problemas de desempenho em uso das moradias executadas com os SCIs são ocasionados por um conjunto de fatores identificados a partir da análise cruzada dos instrumentos. Destacamse entre os problemas levantados a falta de detalhes técnicos dos projetos, sobretudo para a adaptabilidade do sistema construtivo e para a execução das interfaces entre sistema inovador e convencionais; os problemas que decorrem da execução, que se apresentam nos sistemas convencionais, como as instalações de esquadrias, piso, forro e cobertura que, como discutido anteriormente, não provêm da deformação da estrutura; e a falta de manutenção por parte dos usuários e da assistência técnica da moradia, especialmente no que diz respeito à insuficiência de informações no manual de uso, operação e manutenção.

Nos dois casos, conclui-se que o desempenho em uso das vedações inovadoras pode ser considerado satisfatório. Portanto, discutir a importância da avaliação de desempenho em uso, para a homologação definitiva de sistemas construtivos, pode ser considerada relevante na atual conjuntura da política habitacional. Embora os problemas verificados não afetem a segurança e a habitabilidade das moradias avaliadas, a durabilidade dos sistemas inovadores pode ser comprometida progressivamente. Sendo assim, acredita-se que os sistemas podem ser disseminados no âmbito do SiNAT e do PMCMV, desde que melhoradas as questões relacionadas ao detalhe de projeto, à adaptabilidade, à compatibilização com os demais subsistemas e à adoção de procedimentos executivos específicos ao caso, quando se tratar das interfaces. Indica-se, ainda, a elaboração de manuais com ênfase no sistema inovador, de modo a proporcionar garantias estendidas mesmo havendo alterações na moradia, fornecendo, assim, assistência técnica adequada e de acordo com especificidade do problema.

\section{Referências}

AMANCIO, C. R. A; FABRICIO, M. M. Avaliação técnica do produto de construção inovador: contexto brasileiro e internacional. In: FABRICIO, M. M.; ONO, R. Avaliação de desempenho de tecnologias inovadoras: manutenção e percepção dos usuários. Porto Alegre: ANTAC, 2015.

AMANCIO, R. C. B. et al. O sistema brasileiro de avaliação técnica de produtos inovadores para a Construção Civil. In: FABRICIO, M. M.; ONO, R. Avaliação de desempenho de tecnologias inovadoras: manutenção e percepção dos usuários. Porto Alegre: ANTAC, 2015.

ASSOCIAÇÃO BRASILEIRA DE NORMAS TÉCNICAS. NBR 14037: diretrizes para a elaboração de manuais de uso, operação e manutenção das edificações: requisitos para elaboração e apresentação de conteúdo. Rio de Janeiro, 2011.

ASSOCIAÇÃO BRASILEIRA DE NORMAS TÉCNICAS. NBR 15575: desempenho de edificações habitacionais. Rio de Janeiro, 2013.

ASSOCIAÇÃO BRASILEIRA DE NORMAS TÉCNICAS. NBR 16055: parede de concreto moldada no local para a construção de edificações. Rio de Janeiro, 2012b.

ASSOCIAÇÃO BRASILEIRA DE NORMAS TÉCNICAS. NBR 5674: manutenção de edificações: requisitos para o sistema de gestão de manutenção. Rio de Janeiro, 2012a.

ASSOCIAÇÃO BRASILEIRA DE NORMAS TÉCNICAS. NBR 9050: acessibilidade a edificações, mobiliário, espaços e equipamentos urbanos. Rio de Janeiro, 2015. 
BRANDÃO, D. Q.; HEINECK, L. F. M. Significado multidimensional e dinâmico do morar: compreendendo as modificações na fase de uso e propondo flexibilidade nas habitações sociais. Ambiente Construído, Porto Alegre, v. 3, n. 4, p. 35-48, out./dez. 2003.

BRASIL. Ministério das Cidades. Diretriz SiNAT n. 04: sistemas construtivos formados por paredes estruturais de painéis de PVC preenchidos com concreto. Brasília, 2010.

BRASIL. Ministério das Cidades. Diretriz SiNAT n. 05: sistemas construtivos estruturados em peças de madeira maciça serrada, com fechamentos em chapas delgadas (sistemas leves tipo “Light Wood Framing”). Brasília, 2011.

BUCKLEY, R. M.; KALLERGIS, A.; WAINER, L. The emergence of large-scale housing programs: Beyond a public finance perspective. Habitat International, London, v. 54, p. 199-209, 2016.

EUROPEAN COMISSION. Innovative technologies for buildings: EU- funded research to transform the construction sector. 2009. Disponível em:

https://ec.europa.eu/research/industrial_technologies/pdf/construction-090622_en.pdf Acesso em: 21 jul. 2016.

FABRICIO, M. M; LIMA, A. F.; SANCHES I. D. Manutenção predial de sistemas construtivos inovadores. In: SIMPÓSIO INTERNACIONAL DE INICIAÇÃO CIENTÍFICA DA USP, 21., São Paulo, 2013. Anais [...] São Paulo: USP, 2013.

FINANCIADORA DE ESTUDOS E PROJETOS. Roteiro de Inspeção de Sistemas Construtivos (Anexo 2). Subprojeto 5 - Uso e Manutenção. Meta 44 - Desenvolvimento de Procedimentos e Manual para a Avaliação de Desempenho de Sistemas Construtivos Inovadores. Universidade de São Paulo, São Carlos, 2012. p. 382-402. Relatório Parcial do Projeto Inovatec-FINEP.

FLORIANI, R.; BEUREN, I. M; HEIN, N. Análise comparativa da evidenciação de aspectos de inovações em empresas construtoras e multisetoriais. Journal of Information Systems and Technology Management, São Paulo, v. 7, n. 3, p. 693-712, 2010.

FUNDAÇÃO JOÃO PINHEIRO. Centro de estatística e informações déficit habitacional no Brasil 2013 a 2014. Belo Horizonte: A Fundação, 2016.

INSTITUTO DE PESQUISA TECNOLÓGICA. DATec n. 17. Documento de avaliação técnica. Sistema Construtivo de paredes constituídas por painéis de PVC preenchidos com concreto. São Paulo: IPT, ago. 2013.

INSTITUTO FALCÃO BAUER DA QUALIDADE. DATec n. 20. Documento de avaliação técnica. Sistema Construtivo leve em madeira. IFBQ, 2013.

KOWALTOWSKI, D. C. C. et al. Métodos e instrumentos de avaliação de projetos destinados à habitação de interesse social. In: VILLA, D. B.; ORNSTEIN, S. W. (org.). Qualidade ambiental na habitação: avaliação Pós-Ocupação. São Paulo: Oficina de Textos, 2013.

MENDES, M. C. M. et al. Avaliações de habitações em sistemas construtivos inovadores: apresentação de metodologia e resultados da análise de documentação. In: FABRICIO, M. M.; BRITO, A. C.; VITTORINO, F. (org.). Avaliação de desempenho de tecnologias construtivas inovadoras: conforto ambiental, durabilidade e pós-ocupação. 3. ed. Porto Alegre: ANTAC, 2017. v. 3, p. 195-216.

MENDES, M. C. M. A percepção dos moradores sobre o uso de sistemas construtivos inovadores: uma contribuição da Avaliação Pós-Ocupação. São Paulo, 2018. 450 f. Tese (Doutorado em Engenharia Civil) Programa de Pós-Graduação em Arquitetura e Urbanismo, Arquitetura, Urbanismo e Tecnologia, Instituto de Arquitetura e Urbanismo, Universidade de São Paulo, São Paulo, 2018.

MOHIT, M. A.; NAZYDDAH, N. Social housing programme of Selangor Zakat Board of Malaysia and housing satisfaction. Journal of Housing and the Built Environment, v. 26, n. 2, p. 143-164, 2011.

ONO, R. et al. Avaliação de desempenho em uso e manutenção de habitações em sistemas construtivos inovadores. In: FABRICIO, M. M.; BRITO, A. C.; VITTORINO, F. (org.). Avaliação de desempenho de tecnologias construtivas inovadoras: conforto ambiental, durabilidade e pós-ocupação. 3. ed. Porto Alegre: ANTAC, 2017a.

ONO, R. et al. Avaliação Pós-Ocupação: Pré-Teste de instrumentos para verificação do desempenho de Empreendimentos Habitacionais em sistemas construtivos inovadores. Gestão e Tecnologia de Projetos, São Paulo, v. 10, n. 1, p. 64-78, 2015. 
ONO, R. et al. Percepção dos usuários e Avaliação de Desempenho em uso de habitações de sistemas construtivos inovadores. In: FABRICIO, M. M.; BRITO, A. C.; VITTORINO, F. (org.). Avaliação de desempenho de tecnologias construtivas inovadoras: conforto ambiental, durabilidade e pós-ocupação. 3. ed. Porto Alegre: ANTAC, 2017b.

ORNSTEIN, S. W. et al. Avaliação Pós-Ocupação em sistemas construtivos inovadores: considerações finais. In: FABRICIO, M. M.; BRITO, A. C.; VITTORINO, F. (org.). Avaliação de desempenho de tecnologias construtivas inovadoras: conforto ambiental, durabilidade e pós-ocupação. 3. ed. Porto Alegre: ANTAC, 2017.

ORnSteIN, S. W.; ROMERO, M. Avaliação Pós-Ocupação do Ambiente Construído. São Paulo: Studio Nobel, Editora da Universidade de São Paulo, 1992.

PINTO, J. V.; MEDVEDOVSKI, N. S. Contribuições para estudo do Minha Casa Minha Vida para uma cidade de porte médio: Pelotas-RS. In: SIMPÓSIO BRASILEIRO DE QUALIDADE DO PROJETO NO AMBIENTE CONSTRUÍDO, 4., Viçosa, 2015. Anais [...] Viçosa: Universidade Federal de Viçosa, 2015.

PREISER, W. F. E. Post-Occupancy evaluation how to make: buildings work better. Facilities, London, v. 13. n. 11, p. 19-28, oct. 1995.

RUBIN, G. R.; BOLFE, S. A. O desenvolvimento da habitação social no Brasil. Ciência e Natura, Santa Maria, v. 36, n. 2, p. 201-213, maio/ago. 2014.

TUROK, I. Housing and the urban premium. Habitat International, London, v. 54, p. 234-240, 2016.

VILLA, S. B.; ORNSTEIN, S. W. (org). Multimétodos em avaliação pós-ocupação e sua aplicabilidade para o mercado imobiliário habitacional. In: QUALIDADE ambiental na habitação: avaliação pós-ocupação. São Paulo: Oficina de Textos, 2013.

\section{Agradecimentos}

Os autores agradecem a Financiadora de Estudos e Projetos (FINEP) pelo apoio financeiro; aos coordenadores do Projeto Inovatec Finep; as empresas proponentes dos sistemas construtivos, as autoridades locais das prefeituras, a associação dos moradores dos conjuntos habitacionais, aos moradores; aos especialistas participantes; ao Grupo de Pesquisa Arquitec do Instituto de Arquitetura e Urbanismo (IAU-USP); a Universidade de São Paulo pela estrutura e apoio e ao comitê de ética COPEP-UEM pela análise da pesquisa.

Mena Cristina Marcolino Mendes

Departamento de Engenharia Civil | Universidade Estadual de Maringá | Av. Colombro, 5790, Bloco C-67 | Maringá - PR - Brasil | CEP 87020-900| Tel.: (44) 3011-1331 | E-mail: menamarcolino@gmail.com

Márcio Minto Fabricio

Instituto de Arquitetura e Urbanismo | Av. Trabalhador São-Carlense, 400 | São Carlos - SP - Brasil | CEP 13566-590 | Tel.: (16) 3373-9312 | E-mail: marcio@sc.usp.br

\section{César Imai}

Departamento de Arquitetura e Urbanismo | Universidade Estadual de Londrina | Rod. Celso Garcia, PR-445, Km 380 | Londrina - PR Brasil | CEP 86051-990 | Tel.: (43) 3371-4535 | E-mail: cesarimai@gmail.com

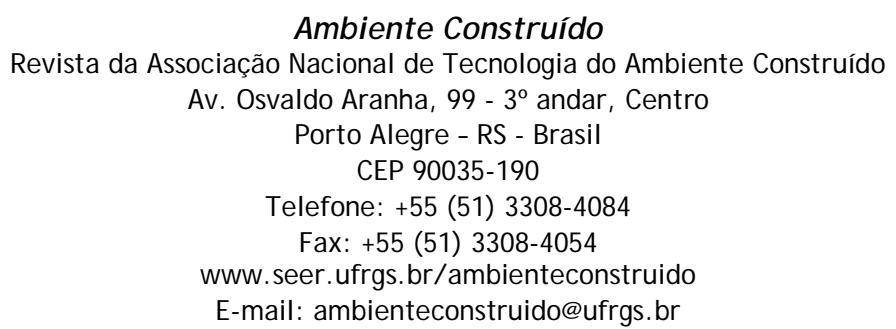

